\title{
Review
}

Matthew Freeman*, Debra Stewart, Charles E. Cunningham and Jan Willem Gorter

\section{Information needs of young people with cerebral palsy and their families during the transition to adulthood: a scoping review}

https://doi.org/10.1515/jtm-2018-0003

Received March 29, 2018; accepted July 19, 2018

\begin{abstract}
The transition to adulthood is a developmental phase which occurs as young people move from adolescence into adulthood. Young people with disabilities, including cerebral palsy (CP), and their families have reported challenges during the transition to adulthood because they are required to move to adult supports and services, which are often fragmented and bring about new questions and expectations to find necessary supports. Young people and their parents have been found to lack information about where to find services in adulthood, how to access the services and what to ask during the transitional process. The aim of this scoping review was to explore the information needs of young people with $\mathrm{CP}$ and their families during the transition to adulthood. The goal is to map the current published evidence within the transition to adulthood literature base to explore what is known about information needs during the transition to adulthood of young people with $\mathrm{CP}$ and their parents. This review seeks to synthesize what is known about information content,
\end{abstract}

\footnotetext{
*Corresponding author: Matthew Freeman, School of Rehabilitation Science, McMaster University, Hamilton, Ontario, Canada; and CanChild Centre for Childhood Disability Research, McMaster University, Hamilton, Ontario, Canada, E-mail: freemamt@mcmaster.ca. http://orcid.org/0000-0001-5084-1877

Debra Stewart: School of Rehabilitation Science, McMaster University, Hamilton, Ontario, Canada; and CanChild Centre for Childhood Disability Research, McMaster University, Hamilton, Ontario, Canada

Charles E. Cunningham: Faculty of Health Sciences, Department of Psychiatry and Behavioural Neurosciences, Michael G. DeGroote School of Medicine, McMaster University, Hamilton, Ontario, Canada

Jan Willem Gorter: Department of Pediatrics, McMaster University, Hamilton, Ontario, Canada; CanChild Centre for Childhood Disability Research, McMaster University, Hamilton, Ontario, Canada; and School of Rehabilitation Science, McMaster University, Hamilton, Ontario, Canada. http://orcid.org/0000-0002-3012-2119
}

timing, methods of provision and delivery. Databases searched were OVID Medline, CINAL, ERIC, EMBASE, PsycINFO, Web of Science, Social Science Abstracts and Sociological Abstracts. Initially 675 articles were retrieved. Four hundred and forty-two articles were selected for title review. Two hundred and five articles remained for abstract review. Seventeen articles were included for fulltext review. Eleven articles were included in this review. Data were organized into five themes: (1) identified information needs during the transition to adulthood (content), (2) identified recommended providers of information during the transition to adulthood (who), (3) identified delivery methods of information during the transition to adulthood (how), (4) identified timing of information delivery of information during the transition to adulthood (when) and (5) location of information provided during the transition to adulthood (where). This review found that young people with $\mathrm{CP}$, their families and adult providers all possess information needs during the transition to adulthood. Young people with CP and their families seek information about what adult services will look like and how to access supports. Adult providers require information about CP. Youth with CP prefer individualized information be delivered to them when needed rather than presented in group sessions or via paper handout. Other recommendations included the development of parent support networks to assist parents in the transition to adulthood. The opportunity to learn from real-life experiences was also viewed as an important source of information as well as method to provide information.

Keywords: cerebral palsy; information needs; scoping review; transition to adulthood.

\section{Introduction}

The transition to adulthood is a process in which young people move from one developmental stage to another from adolescence to early adulthood. Entering adulthood requires a young adult to adopt new roles and expectations 
while gradually taking control of their own life. Arnett [1] describes this developmental phase as one in which young people begin exploring options for the future. This may include exploring postsecondary education, finding employment and pursuing long-term relationships [1]. Nguyen and Baptiste [2] note that the transition to adulthood for youth with disabilities and their families represents a shift in culture and service delivery. The pediatric system tends to be more integrated whereas adult services are less centralized and more fragmented [2-5]. Inherent within the exploration of new options, young people start asking questions and seek information, such as, do I want to attend a postsecondary institution close to my family home? or how can I access transportation schedules so that I can get to work? For youth with disabilities who have the same aspirations for adult life as their nondisabled peers [6], their questions may be similar but may come with disability specific information needs. For example, when it comes to selecting a postsecondary institution, a young person with cerebral palsy (CP) may ask, does the school offer attendant care?

The provision of information to young people and their families in the transition to adulthood is considered best practice $[7,8]$. Qualitative literature discussing the experiences of moving from a pediatric system to the adult system from Canada [3], Sweden [9] and the United States [4] describe a lack of support regarding how to navigate adult care systems and find answers to questions. Literature also highlights gaps in the knowledge of young people with CP on topics such as their physical function [4, 10], and how their physical function or pain influences their participation in meaningful activities [11-13].

While providing information to families is a cornerstone of family-centred care [14], pediatric service providers often experience discomfort providing information to youth and families [15]. Reasons for this include clinicians feeling uncertain about whether they are providing the right information and having more comfort in giving direct 'hands-on' or practical service to families [15]. Current literature now recognizes that the provision of information to young people with $\mathrm{CP}$ and their families during the transition to adulthood is important [16], however specifics about information delivery, its timing and the methods of provision during the transition process have yet to be synthesized.

The aim of this scoping review is to map the current published evidence within the transition to adulthood literature to explore what is known about information needs during the transition to adulthood of young people with $\mathrm{CP}$ and their parents. This review seeks to synthesize what is known about information content, timing, methods of provision and delivery.

\section{Methods}

Scoping reviews seek to examine and map current knowledge and evidence regarding a phenomenon by "systematically searching, selecting and synthesizing evidence" [17] (p. 1292). Our scoping review is guided by the framework proposed by Colquhoun and colleagues [17], which synthesizes two previous framework iterations originating with Arksey and O'Malley [18] and Levac, Colquhoun and O'Brien [19]. Within this framework there are five recommended steps with an optional sixth focusing on dissemination of findings and consultation with colleagues, which was not used in this review.

\section{Purpose of the review and the research team}

In seeking to understand the information needs of young people with $\mathrm{CP}$ and their families, this review explores, in addition to content areas, other areas of information delivery, including suggestions from professionals and preferences from stakeholders with respect to timing of information delivery (when) and in respect to how information is delivered. The research team was comprised of two content experts in transition to adulthood for youth with disabilities (JWG and DS), a graduate student in rehabilitation science living with $\mathrm{CP}$ (MF), and a researcher familiar with information needs research and provision strategies (CC).

\section{Identifying relevant studies}

The inclusion criteria were peer-reviewed papers with full text available explicitly referencing the transition to adulthood, CP, and information needs or provision within the abstract. To assist in finding relevant literature the following databases were searched: OVID Medline, CINAL, ERIC, EMBASE, PsycINFO, Web of Science, Social Science Abstracts and Sociological Abstracts. No limitations were placed on year of publication or language of publication during the search, and all full text articles reviewed were published in English.

MF conducted the database searches in July 2017 in consultation with a health science librarian. The research team recognized that often a diagnosis of $\mathrm{CP}$ may be included in more general studies examining the transition to adulthood for youth with disabilities, which include $\mathrm{CP}$ as well as other conditions. Therefore, to be as inclusive as possible, major subject headings for $\mathrm{CP}$, childhood disability and transition to adulthood or transitions were used on recommendation by the health sciences librarian. Data for the scoping review were managed using 
bibliographic management software and the creation of Microsoft Excel spreadsheets that allowed each reviewer to select their inclusion or exclusion option as well as provide a rationale, if needed.

\section{Study selection}

A summary of the study selection process is shown in Figure 1. Searching of databases retrieved 675 articles. After removing duplicates, 442 articles moved forward to title review. MF and DS performed the title review and met to discuss their decisions as well as reasoning to ensure agreement and reinforce the aims of the review. Following title review, 205 articles remained for abstract review. MF and DS reviewed all abstracts and CC acted as judge in areas of disagreement. Seventeen articles were included for full-text review by MF and DS. During full-text review, six articles were removed as they did not discuss information needs, CP and the transition to adulthood. The characteristics of the 11 included studies are summarized in Table 1.

\section{Charting the data}

Data were then extracted by MF from eleven articles and reviewed by DS and JWG. All articles were read and data pertaining to information needs and/or provision were charted (Table 2).

\section{Collating, summarizing and reporting the results}

An a priori coding scheme was developed using summative content analysis [20]. Patterns emerging from the raw data were then organized by identified information needs during transition (content), identified providers of information during transition (who), identified delivery methods of information during transaction (how), identified timing of information delivery of information during transition (when) and location of information provided during transition (where). It was recognized that it was necessary to make purposeful distinctions between

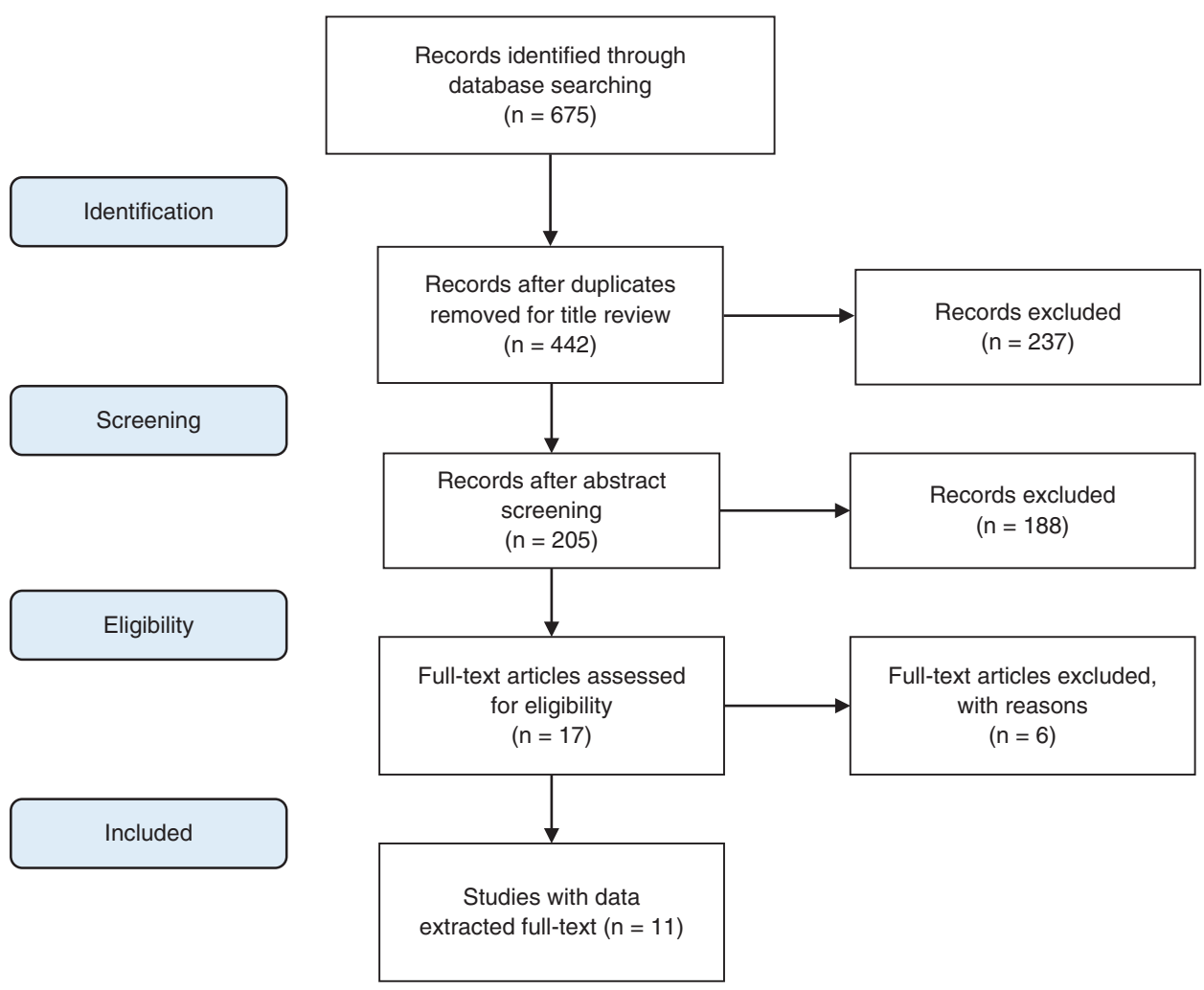

Figure 1: PRISMA study selection flow diagram. 


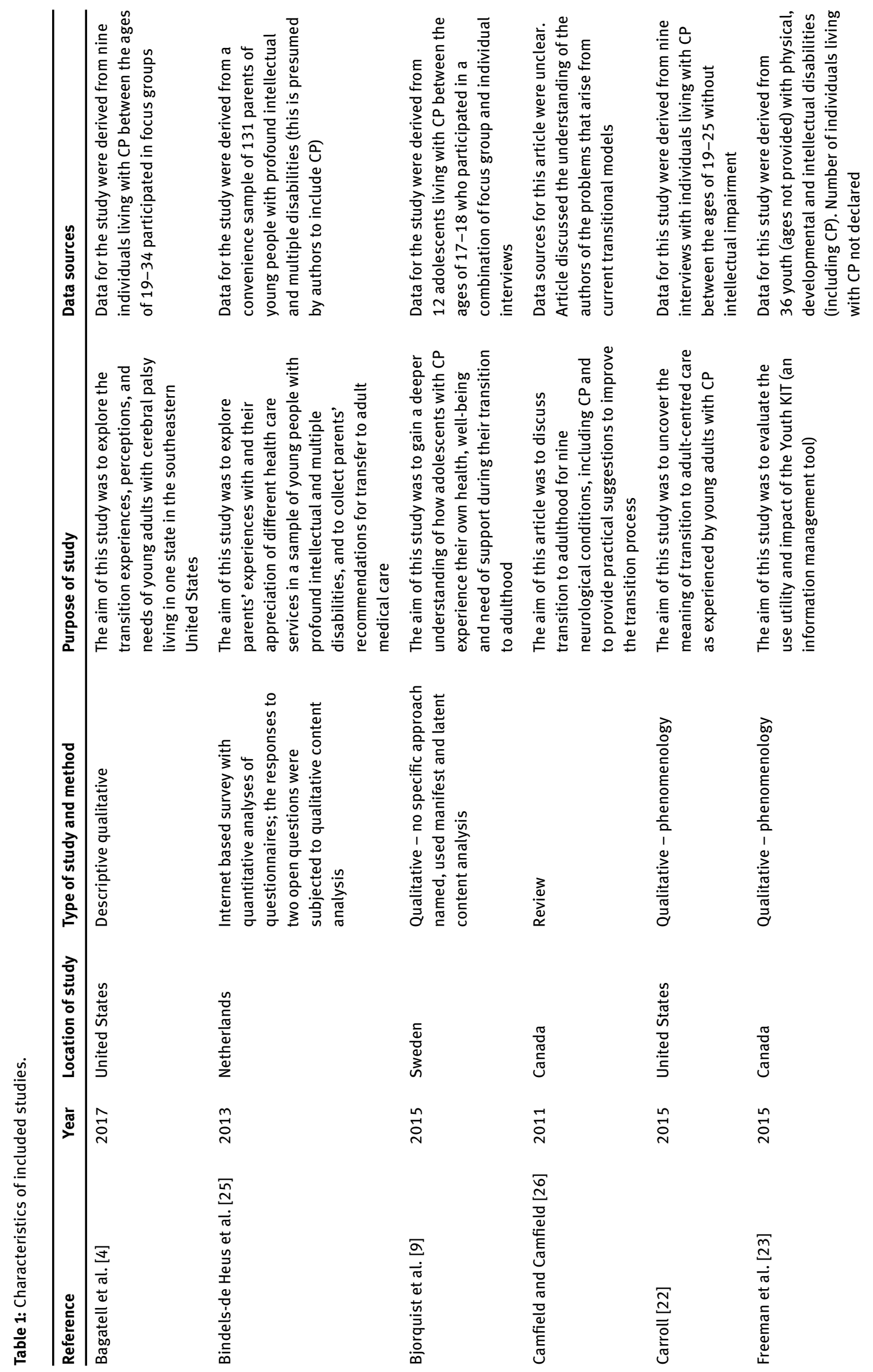




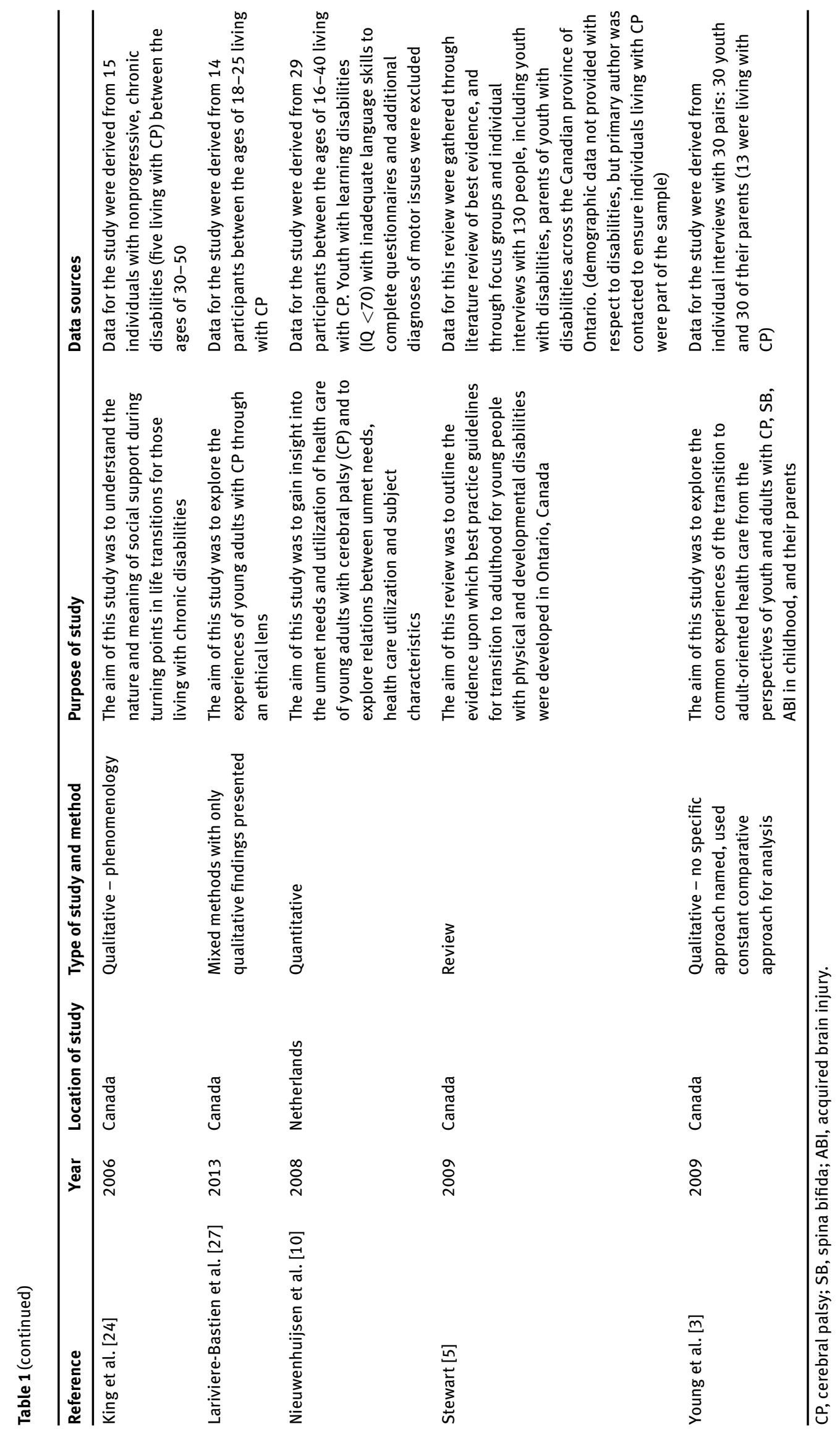




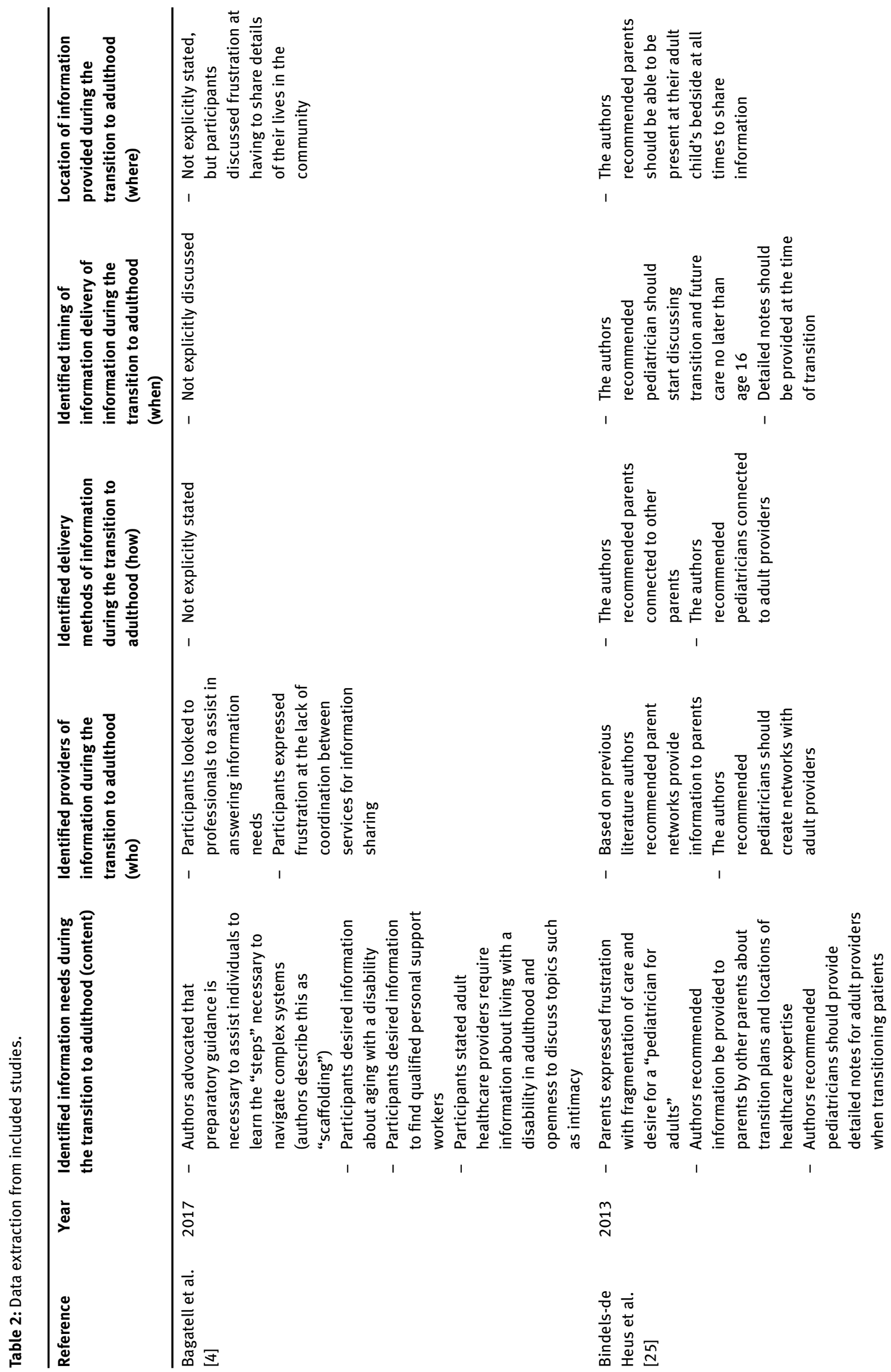




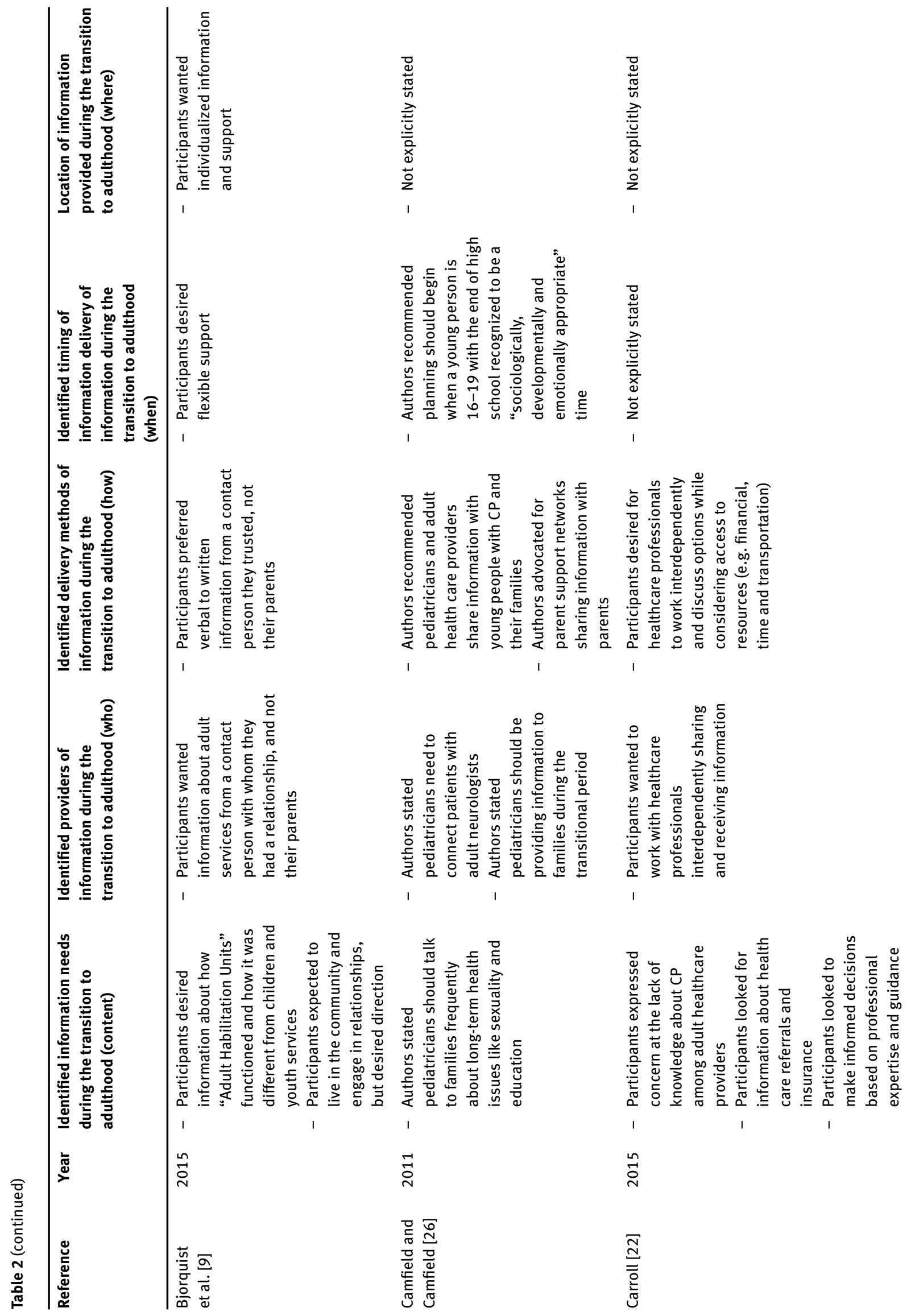




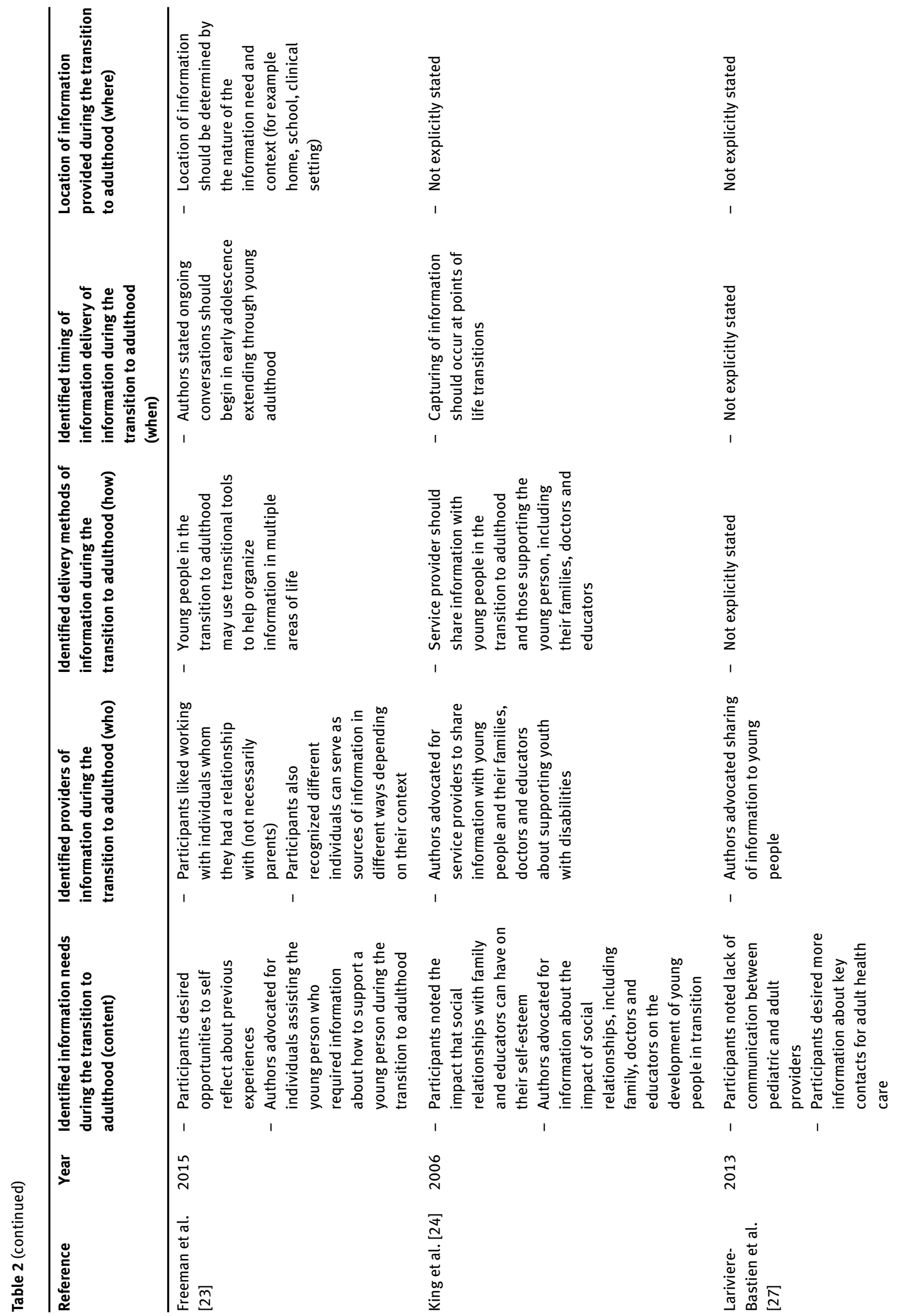




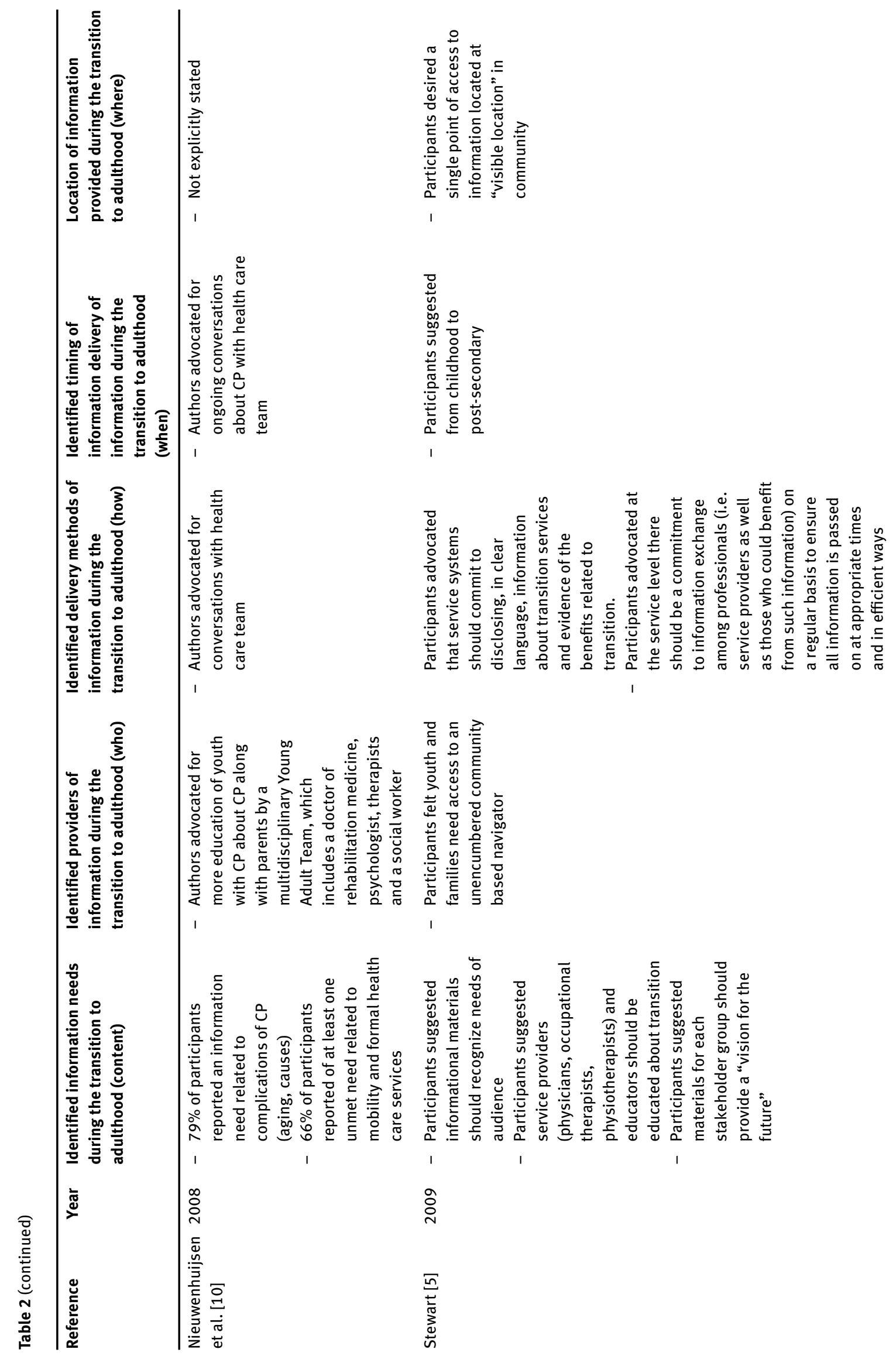




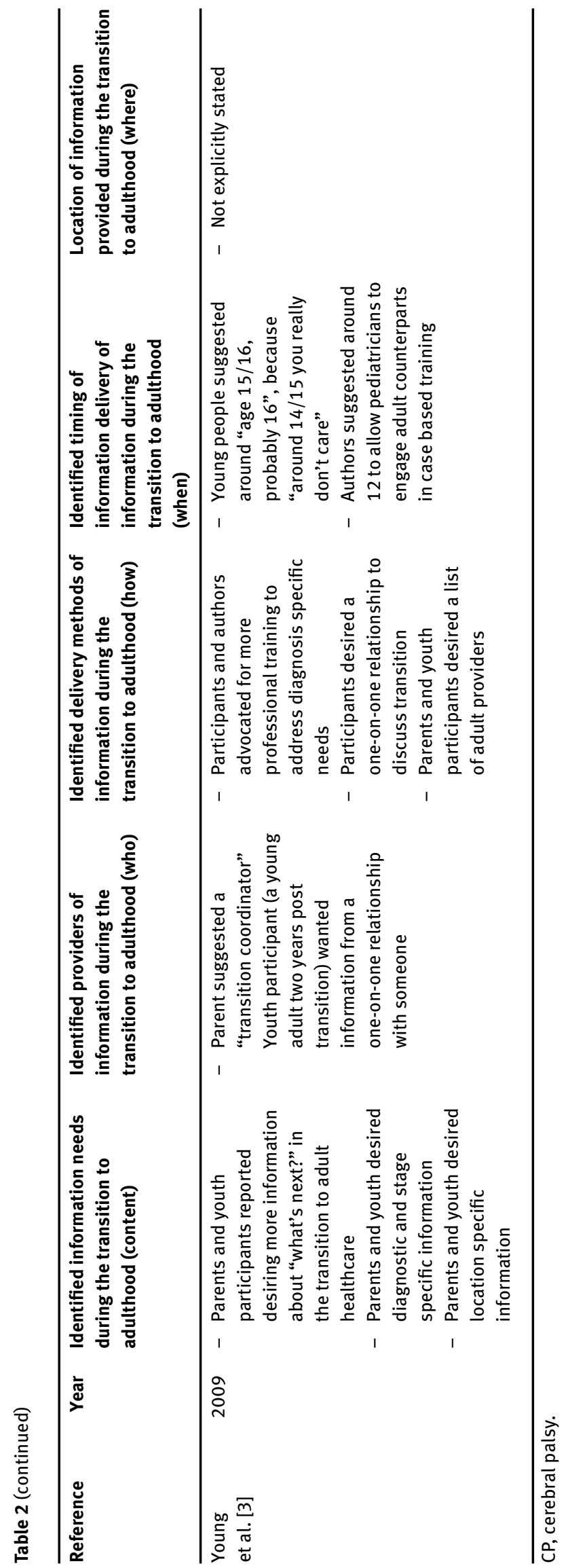


recommendations from participants in research versus recommendations from authors when summarizing the findings. These organizational categories consider the idiosyncratic and individual nature of information needs [21], which requires an examination of the preferences of knowledge users. Although this coding structure was developed a priori, ultimately these categorizations were validated by the review as many studies addressed these attributes in their findings or discussions.

\section{Results}

Eleven articles were reviewed. All articles were retrieved from health-oriented databases. Six of the articles were qualitative studies [3, 4, 9, 22-24], two were quantitative studies [10, 25], two were reviews [5, 26] and one was a mixed methods study [27], though only qualitative findings from this latter study were reported. Six of the studies collected data in Canada [3, 5, 23, 24, 26, 27], two studies collected data in the United States [4, 22] and two collected data in the Netherlands [10, 25]. Seven articles focused on healthcare transitions $[3,9,10,22,25-27]$, one article explored multiple dimensions of transition of youth with $\mathrm{CP}$ including managing their own care, managing government assistance and supports and healthcare transitions [4], one article explored the development of best practice guidelines [5], one article focused on the development and evaluation of an information management tool during the transition to adulthood [23], and one article focused on the role of social support during life transitions [24].

All articles reviewed recognized the importance of information to assist individuals in making decisions. Three main groups were recognized as having information needs in these articles: youth with CP, their families and clinicians in both pediatric and adult health care settings. Stewart [5] also identified educators as having information needs and a role in assisting youth with disabilities, including $\mathrm{CP}$, in the transition to adulthood.

\section{Identified information needs during the transition to adulthood (content)}

The majority of the articles (7 out of 11) focused exclusively on healthcare transitions [3, 10, 22, 25-27]. The content of information targeted health-related domains such as aging with CP [10], sharing of information between pediatric and adult service providers $[10,22,26]$ and how to share information with service providers, such as personal care attendants, that may not necessarily have an understanding or skill set in dealing with adults with $\mathrm{CP}[4]$.

Young and colleagues [3] found that both young people with $\mathrm{CP}$ and their parents sought information about where to find medical care entering adulthood. Nieuwenhuijsen et al. [10] found a need for young people to learn more about $\mathrm{CP}$ suggesting that disability specific information is often delivered to parents during a child with CPs early years, but limited information about the condition and changes in impairments is provided to children, adolescents or young adults as they age. Camfield and Camfield [26] expanded questions about individual function to include questions of sexual health. Parents of youth in transition often shared similar information needs with their children, but Bindels-de Heus and colleagues [25] highlighted information needs of parents of young people living with $\mathrm{CP}$ who also live with an intellectual disability. For this subgroup of parents, information about differences in adult care, such as the fragmentation of care versus a single pediatrician, and differences in the role of parents in the adult system advocating for their children [25] were key considerations when thinking about the future. Young and colleagues [3], Bindels-de Heus and colleagues [25] and Camfield and Camfield [26] discussed the importance of the continuing education of adult providers to further understand the needs of young people with $\mathrm{CP}$ and their families.

Four of the 11 articles were not specific to any transitional domain (e.g. healthcare or education). Instead, authors discussed the transition to adulthood broadly [4, $5,9,23]$. Bagatell et al. [4] found in addition to health, young people also have to navigate new systems and find information or correct contacts to establish financial support and find employment or work while receiving benefits. Bjorquist et al. [9], found a desire for information about supported independence from their families, adult relationships, intimate relationships and finding housing. Stewart [5], in addition to the previous domains identified, also recognized that young people with $\mathrm{CP}$ are a part of the education system and educators therefore require information about transition to adulthood, which is important when planning their postsecondary education journey. Freeman et al. [23] discussed the development of a transitional tool for adolescents to organize information in various domains, such as health, employment, socialization and education. One of the benefits of the transitional tool was that it broke down information needs into manageable pieces for individuals and provided worksheets with developmentally sequenced questions that built on pre-existing knowledge (i.e. street address, intersections 
around the family home and the local accessible public transit bus route).

In summary, youth with $\mathrm{CP}$ and their families are looking for information during the transition to adulthood not only about their physical health, but also their social and emotional health. They are also looking for information about opportunities to further participate in their communities in adult life. The articles in this review also recognize that individuals interacting with young people with $\mathrm{CP}$ and their families also have information needs. This includes doctors, educators and those delivering governmental services.

\section{Identified recommended providers of information during the transition to adulthood (who)}

Preferences for provision of information during the transition to adulthood is different for young people with CP, their families and pediatric and adult providers. For young people and their families, several studies recognized that they can be both providers of information and receivers of information as they experience this transition [3, 4, 9, 22, 25]. For example, the healthcare transition literature reviewed highlighted the need for young people and their families to share information about themselves with their new practitioners in the adult world [26, 27]. At the same time, these studies also recognized the need for both pediatricians and adult clinicians to provide information to families to assist them in preparing for and navigating the new system and expectations.

Although it was found that young people with $\mathrm{CP}$ and their families should be viewed as having expertise about their own experience, some of the qualitative studies challenged this perspective with nuance. Carroll [22] introduced the concept of the "expert novice" as young people are trained by their pediatric care teams to understand their conditions and be experts. Entering at the adult world, they feel that they have an inadequate knowledge base and level of expertise. Other studies in this review also recognized young people may not possess the necessary skills to best share information about themselves [3, 27].

Studies about information needs also recognized the importance of social support during the transition to adulthood for youth and families. Although many studies advocated for an individual to assist youth and families navigating systems $[4,5,9,10,22-26]$, who the individual was or should be varied among studies. The articles focusing primarily on healthcare transitions indicated that clinicians, such as a nurse [22] or social worker, or therapist [10] could act as a navigator Regardless of the discipline of the individual clinician, the studies reviewed made the important point that the navigator should be someone the individual connects with on a regular basis [10, 22, 23, 26]. In contrast, Carroll [22], Freeman et al. [23] and Stewart [5] considered the multidimensional and contextual nature of navigation and mentorship and argued for support coming from an individual that was a fit between the young person's interests and the mentor's interests and knowledge. An educational assistant may be helpful when assisting a young person with educationrelated information, but a friend may be more helpful in assisting with information about social activities. In summary, youth with $\mathrm{CP}$ and their families are looking to receive information from individuals close to them who can act as a navigator. Importantly the "fit" between young people with $\mathrm{CP}$ or their families and the navigator is a key factor to consider.

\section{Identified delivery methods of information during the transition to adulthood (how)}

Bjorquist et al. [9] identified two important findings: First, information was preferred to be delivered verbally, and second, young adults preferred information be delivered by individuals other than their parents. In addition to verbal face-to-face communication, other studies recognized that information can also be gathered through real-life experiences. Three articles advocated for young people to be connected with adult service providers early on in their transitional process $[3,4,27]$ so that relationships can be developed and an understanding of expectations on both sides of the clinical relationship can be developed [3, 25, 27]. Freeman et al. [23] provided support for young persons to learn through experiences and to be given the opportunity to reflect on those experiences and use this new information to assess change throughout the course of their developmental journey.

For parents, delivery methods included verbal or faceto-face communication with clinicians as well as peer support. Bindels-de Heus and colleagues [25] advocated parent support networks which can play a key role in assisting parents during the transition to adulthood by helping to develop "transitional plans" with families. Camfield and Camfield [26] also identified the personal connections of parent networks as important delivery methods of information, pointing out that doctors and families may change their geographical location over time 
and require new information and networks for their communities.

None of the articles in this review discussed providing written information to families; however, Stewart advocates for service systems to provide information in "clear language” (p. 171). The sharing of written information was discussed within the context of sharing between service providers [5, 25-27].

In summary, youth with $\mathrm{CP}$ and their families require information delivered to them by individualized information methods. Examples of individualized information included young people with CP preferring information be delivered to them verbally rather than in written format. Parents of young people with $\mathrm{CP}$ also preferred face-toface communication.

\section{Identified timing of information delivery of information during the transition to adulthood (when)}

There is no agreement about the timing of information delivery to young people and their parents during the transition to adulthood, but an analysis of recommendations suggests that sharing of information should begin at least at the beginning of the transitional phase [3, 5, 22, 26], which is typically between ages $14-16[3,25,26]$. Stewart [5] broke down the transition to adulthood into a series of phases described as preparation, journey and landing. In the preparation phase, youth may begin learning more about themselves and using transitional tools such as the Youth KIT [23] to gather and organize information. In cases where recommendations were made for young people and their families to experience connecting with adult services early, the suggested time was around 16 years [26, 27]. As the young person is experiencing the transition to adult services, suggestions included pediatric providers making every attempt to communicate and share medical information with adult providers and setting up networks to ensure that all providers have a good understanding of childhood disability and its management $[3,4,25,26]$. Regardless of the lack of specificity of the timing of the information sharing, studies make clear that information sharing is a dynamic and ongoing iterative process in which the development of the young person, their expectations and abilities should be considered [23, 24]. Stewart [5] suggests that once a young person and their family have transitioned or "landed", new information needs may arise stemming from a change in context.

In summary, the transition to adulthood for youth with $\mathrm{CP}$ and their parents is a dynamic and interactive process that requires an ongoing conversation, which should typically begin in early adolescence and should always be approached in a developmentally appropriate fashion.

\section{Location of information provided during the transition to adulthood (where)}

The location of information was only explicitly discussed by three of the reviewed articles. The most specific recommendations came from Stewart [5] who advocated a central point of access within communities that is visible, though no guidelines are provided. Bjorquist et al. [9] shared that youth did not want their information provided in group settings, but rather individualized. Freeman et al. [23] built upon the theme of individualized information asserting that the location of information delivery is dependent upon the contextual nature of the information need. Interestingly, though not related specifically to location of information, participants in Bagatell et al. [4] expressed frustration at having to share information to providers repeatedly in different contexts.

In summary, the location of information delivery is dependent upon the individual for both youth with $\mathrm{CP}$ and their parents. The individualization is determined by the information need and the individual's context.

\section{Discussion}

The primary objective of this review was to identify what is known within published literature about the information needs of transitioning young people with $\mathrm{CP}$ and their families. We sought to explore what was known about the content of information needs (what) as well as preferences for timing (when), provision (who), delivery method (how), and location of that information (where). This review shows that young people with $\mathrm{CP}$ and their families, reported similar challenges addressing their information needs and desired similar strategies to improve transition experiences for themselves and others. Young people with $\mathrm{CP}$ and their parents desire individualized information about what to expect during the transition to adulthood, including information about health, education, social opportunities and intimate relationships. Both young people with $\mathrm{CP}$ and their parents desire support systems to assist them with addressing information needs, and delivery of information in the method and location that they desire. 


\section{Contextualizing the findings and service implications}

Many of the findings emerging in this review come from qualitative studies that advance not only our understanding of information needs, but also insight into the burden felt when individuals and their families were unable to access the information when they needed it $[3,4,9]$. Repeated across studies was the theme of "falling off a cliff" or a sense of isolation [3-5, 10, 26].

Nguyen and Baptiste's [2] discussion of acculturation provides useful insight into why this sense of isolation may be occurring. Within pediatric systems there is an expectation of "family centred practice" often with the pediatrician at the centre of care [25]. Parents of children with CP have reported grieving the loss of a pediatrician figure to assist with care [25]. Without centralized service delivery, it is reported that parents are often having to fill the gap by seeking their own information $[3,25]$ and advocating for their children.

The notion that the individual with $\mathrm{CP}$ and their family are the experts of their own lived experience is an underpinning of family centred practice [11]; however, when thinking about information needs and the provision of information we must explore this concept with a critical eye. Expertise about one's impairments or conditions should be viewed within the context of the individual. For example, Caroll [22] found that young adults with CP often recognize the limitations of their own knowledge and look to professionals to provide suggestions based on clinical experience and expertise. Within the context of informational support, King et al. [24] suggest that social support networks play an important role as information providers, not only in providing direct answers, but also making suggestions which allow for the exploration of new options. However, King et al. [24] also recognized and exposed some of the potential conflicts and negative attitudes encountered by individuals when looking for social support, such as preconceived notions about ability to achieve goals within the context of an individual's perceived functional abilities, which was similar to those found in Freeman et al. [23]. Bagatell and colleagues [4] argue that, during the transition to adulthood, there is a difference between policy objectives and reality. Although policies advocate for young people with disabilities and their families to direct their own services and make independent choices about their future from an array of options, young people may not possess enough information to make informed choices about the options available.
Bjorquist et al. [9] explored the health and well-being of older adolescents aged 17 and 18 who preferred information be provided by individuals other than their parents. From a developmental perspective, this is congruent with theories of emerging adulthood [1], which suggests that individuals begin to rely less on their family to construct their worldview. This scoping review also highlighted the need for formal information support providers (e.g. doctors, educators or rehabilitation professionals) to move away from discussing the specific domains of an individual's life and rather looking at the whole person in context. For example, an individual client may be interested to know about the relationship between aging and physical functioning within the context of intimate relationships [28].

Clinicians working with young people with $\mathrm{CP}$ and their families in the transition to adulthood should be willing to provide clinical information and advice, and answer direct questions from their clients, as well as provide prompting to the young person and their families to ask questions. That said, it is recognized that clinicians have information needs of their own and may not have the opportunity to get a holistic history before seeing a client. Nevertheless, it is advisable for clinicians to adopt a "shared agency" approach recommended by Gorter and Gibson [29], which allows for mutual learning on both the part of provider and client. Nieuwenhuijsen and colleagues [10] provide a helpful list of questions young people are seeking answers to, which is a good guide for clinicians. For example, young people want to know about sexuality or driving a car, and this can provide opportunity for clinicians to inquire about whether young people or their families have considered expanding relationships or transportation opportunities. Asking these questions is an example of a "shared agency" approach.

\section{Opportunities for future research}

Many of the articles in our scoping review targeted information needs in the context of the healthcare transition. It is necessary to further study whether the barriers faced with giving and getting information during healthcare transition are also barriers faced in other transitional domains, including leaving the family home or finding employment. In the domain of employment, it is known that young people with CP and other lifelong conditions have difficulty communicating information about their accommodation needs with their employer [30]. One question is the degree that individuals with 
$\mathrm{CP}$ are required to act as their own expert when advocating accommodations within the workplace or whether employers are working with professionals to universally accommodate individuals with disabilities within the workplace.

The findings in our review suggest that youth with CP prefer to receive information from people they have relationships with. Therefore, future research may explore the development and maintenance of parent supports or peer supports for youth with CP and whether they assist them in meeting their information needs and in making the cultural shift inherent in the pediatric and adult service and support systems. While a navigator was identified as being helpful and important in the literature, there is a lack of evidence on its effectiveness. Future research therefore should incorporate pragmatic effectiveness studies [31] to evaluate the effects of a navigator and the 'active ingredients' of such an intervention. There are also questions about whether navigation needs to occur in person or can be done over the Internet [32]. In this review the use of a mentor through internet-based connections was not mentioned; however, within the context of health information more generally as well as transition literature, internetbased strategies are emerging [32, 33], but the need for approaches tailored to the needs of the individual receiving support is highlighted.

\section{Limitations and considerations}

The use of scoping review methodology to synthesize knowledge is acknowledged within the context of this review. Scoping reviews examine all evidence to "map" concepts and, unlike systematic review methods, they do not include a stage where evidence is appraised for overall quality [19]. Our goal in this review was to understand identified information needs during the transition to adulthood published in journals after having been through the peer review process; however, we do recognize that some qualitative studies reviewed had smaller sample sizes than recommended for the chosen methodological approach. Examining the qualitative studies as a group, the repetition of themes across geographical locations lends to overall transferability of findings to other populations of young people with CP in the transition to adulthood. Nevertheless, we recognize that the studies reviewed are from "Western" nations and may have a bias toward individuals and families with long-term engagements with the pediatric healthcare system. Future research should explore the applicability of these findings to hard-to-reach families and individuals living with $\mathrm{CP}$ and their families immigrating from or living in non-Western nations. We also recognize that this review did not incorporate grey literature, which may not be formally published, aimed at providing information to young people with $\mathrm{CP}$ and their families in the transition to adulthood.

Another issue arising out of this review is terminology: only two of the 11 articles reviewed used keywords relating to information or knowledge. Prioritizing information as a keyword will help further define and develop the literature base about information needs for youth and families during the transition to adulthood.

\section{Conclusion}

Our scoping review identifies what is known about information needs of youth with CP during the transition to adulthood, their families, pediatric clinicians, and future adult healthcare providers. Information provided to individuals with $\mathrm{CP}$ and their families cannot be prescriptive, but rather responsive to the needs of the developing individual in multiple changing contexts over time. Even in a small body of published literature we found a consistent pattern of information needs regarding healthcare transition as well as transitions in other life domains throughout this developmental process. Scarce literature is available with less consistency to guide the optimal method of information delivery, in terms of when, by who, how and where.

Acknowledgments: The authors wish to thank Alice Soper for her assistance reviewing the manuscript and assisting with the preparation. Dr. Cunningham's participation was supported by the Jack Laidlaw Chair in Patient Centered Health Care.

\section{Author Statement}

Research funding: Authors state no funding involved. Conflict of interest: The authors declare that they have no conflict of interest.

Informed consent: Informed consent is not applicable. Ethical approval: The conducted research is not related to either human or animals use.

\section{References}

1. Arnett JJ. Emerging adulthood: a theory of development from the late teens through the twenties. Am Psychol 2000;55:469-80. 
2. Nguyen T, Baptiste S. Innovative practice: exploring acculturation theory to advance rehabilitation from pediatric to adult "cultures" of care. Disabil Rehabil 2015;37:456-63.

3. Young NL, Barden WS, Mills WA, Burke TA, Law M, Boydell K. Transition to adult-oriented health care: perspectives of youth and adults with complex physical disabilities. Phys Occup Ther Pediatr 2009;29:345-61.

4. Bagatell N, Chan D, Rauch KK, Thorpe D. "Thrust into adulthood": transition experiences of young adults with cerebral palsy. Disabil Health J 2017;10:80-6.

5. Stewart D. Transition to adult services for young people with disabilities: current evidence to guide future research. Dev Med Child Neurol 2009;51:169-73.

6. Shikako-Thomas K, Lach L, Majnemer A, Nimigon J, Cameron K, Shevell M. Quality of life from the perspective of adolescents with cerebral palsy: “I just think I'm a normal kid, I just happen to have a disability”. Qual Life Res 2009;18:825-32.

7. Stewart D, Freeman M, Law M, Healy H, Burke-Gaffney J, Forhan M, et al. Best Journey to Adult Life for Youth with Disabilities: an evidence-based model and best practice guidelines for the transition to adulthood for youth with disabilities. Hamilton, Ontario: CanChild Centre for Childhood Disability Research; 2009. Available from: http://transitions.canchild.ca/ en/OurResearch/bestpractices.asp?_mid_ $=2594$.

8. Bolger A, Vargus-Adams J, McMahon M. Transition of care in adolescents with cerebral palsy: a survey of current practices. PM R 2017;9:258-64.

9. Bjorquist $E$, Nordmark E, Hallstrom I. Living in transition experiences of health and well-being and the needs of adolescents with cerebral palsy. Child Care Health Dev 2015;41:258-65.

10. Nieuwenhuijsen C, van der Laar Y, Donkervoort $M$, Nieuwstraten W, Roebroeck ME, Stam HJ. Unmet needs and health care utilization in young adults with cerebral palsy. Disabil Rehabil 2008;30:1254-62.

11. Stewart DA, Lawless JJ, Shimmell LJ, Palisano RJ, Freeman M, Rosenbaum PL, et al. Social participation of adolescents with cerebral palsy: trade-offs and choices. Phys Occup Ther Pediatr 2012;32:167-79.

12. Nieuwenhuijsen C, Donkervoort M, Nieuwstraten W, Stam HJ, Roebroeck ME, Transition Research Group South West N. Experienced problems of young adults with cerebral palsy: targets for rehabilitation care. Arch Phys Med Rehabil 2009;90:1891-7.

13. Sienko SE. An exploratory study investigating the multidimensional factors impacting the health and well-being of young adults with cerebral palsy. Disabil Rehabil 2018;40:660-6.

14. Darrah J, Wiart L, Magill-Evans J, Ray L, Andersen J. Are familycentred principles, functional goal setting and transition planning evident in therapy services for children with cerebral palsy? Child Care Health Dev 2012;38:41-7.

15. King GA, Tucker MA, Baldwin PJ, Laporta JA. Bringing the life needs model to life: implementing a service delivery model for pediatric rehabilitation. Phys Occup Ther Pediatr 2006;26:43-70.

16. Syverson EP, McCarter R, He J, D’Angelo L, Tuchman LK. Adolescents' perceptions of transition importance, readiness, and likelihood of future success: the role of anticipatory guidance. Clin Pediatr 2016;55:1020-5.
17. Colquhoun HL, Levac D, O’Brien KK, Straus S, Tricco AC, Perrier L, et al. Scoping reviews: time for clarity in definition, methods, and reporting. J Clin Epidemiol 2014;67:1291-4.

18. Arksey H, O'Malley L. Scoping studies: towards a methodological framework. Int J Soc Res Methodol 2005;8:19-32.

19. Levac D, Colquhoun H, O’Brien KK. Scoping studies: advancing the methodology. Implement Sci 2010;5:69.

20. Hsieh H-F, Shannon SE. Three approaches to qualitative content analysis. Qual Health Res 2005;15:1277-88.

21. Cole C. A theory of information need for information retrieval that connects information to knowledge. J Am Soc Inf Sci Technol 2011;62:1216-31.

22. Carroll EM. Health care transition experiences of young adults with cerebral palsy. J Pediatr Nurs 2015;30:e157-64.

23. Freeman M, Stewart D, Shimmell L, Missiuna C, Burke-Gaffney J, Jaffer S, et al. Development and evaluation of The KIT: Keeping It Together (TM) for Youth (the 'Youth KIT') to assist youth with disabilities in managing information. Child Care Health Dev 2015;41:222-9.

24. King G, Willoughby C, Specht JA, Brown E. Social support processes and the adaptation of individuals with chronic disabilities. Qual Health Res 2006;16:902-25.

25. Bindels-de Heus K, van Staa A, van Vliet I, Ewals F, Hilberink SR. Transferring young people with profound intellectual and multiple disabilities from pediatric to adult medical care: parents' experiences and recommendations. Intellect Dev Disabil 2013;51:176-89.

26. Camfield P, Camfield C. Transition to adult care for children with chronic neurological disorders. Ann Neurol 2011;69: 437-44.

27. Lariviere-Bastien D, Bell E, Majnemer A, Shevell M, Racine E. Perspectives of young adults with cerebral palsy on transitioning from pediatric to adult healthcare systems. Semin Pediatr Neurol 2013;20:154-9.

28. Wiegerink DJ, Roebroeck ME, Donkervoort M, Cohen-Kettenis PT, Stam HJ. Social, intimate and sexual relationships of adolescents with cerebral palsy compared with able-bodied age-mates. J Rehabil Med 2008;40:112-8.

29. Gorter JW, Gibson BE. Independence in adulthood: ethical challenges in providing transitional care for young people with neurodevelopmental impairments. In: Rosenbaum P, Ronen GM, Racine E, Johannesen J, Bernard D, editors. Ethics in child health: principles and cases in neurodisability. London, UK: Mac Keith Press, 2016:335-48.

30. Benner JL, Hilberink SR, Veenis T, van der Slot WM, Roebroeck ME. Course of employment in adults with cerebral palsy over a 14-year period. Dev Med Child Neurol 2017;59:762-8.

31. ClinicalTrials.gov [Internet]. Bethesda (MD): National Library of Medicine (US). Identifier NCT03342495; Evaluating Innovations in Transition from Pediatric to Adult Care - The Transition Navigator Trial (TNT); 2017 Nov 17 [cited 2018 June 06]. Available from: https://clinicaltrials.gov/ct2/show/NCT03342495.

32. Gorter JW, Stewart D, Cohen E, Hlyva O, Morrison A, Galuppi B, et al. Are two youth-focused interventions sufficient to empower youth with chronic health conditions in their transition to adult healthcare: a mixed-methods longitudinal prospective cohort study. BMJ Open 2015;5:e007553.

33. Ali K, Farrer L, Gulliver A, Griffiths KM. Online Peer-to-Peer Support for Young People with Mental Health Problems: a systematic review. JMIR Ment Health 2015;2:e19. 